\title{
A influência socieconômica e cultural no brincar de pré-escolares
}

\author{
Luzia Iara Pfeifer ${ }^{1}$ \\ Patrícia Gonçalves Rombe \\ Jair Licio Ferreira Santos \\ Universidade de São Paulo, Ribeirão Preto-SP, Brasil
}

\begin{abstract}
Resumo: Considerando que o contexto econômico influencia o brincar de crianças, este trabalho teve por objetivo analisar as diferenças entre os brinquedos utilizados por crianças de duas diferentes classes socioeconômicas. Os dados foram coletados junto a 50 mães de crianças com idade entre três e seis anos, metade pertencentes à classe econômica A2 (Grupo 2), e a outra metade pertencente à classe econômica $\mathrm{D}$ (Grupo 1), segundo o Critério Brasil. Os resultados apontam para a existência de diferenças significativas quanto ao uso do computador $(p=0,000)$, jogos de tabuleiro $(p=0,023)$, jogos de $\operatorname{armar}(p=0,042)$ e jogo de botão $(p=0,012)$, mais presentes no Grupo 2 , e quanto ao uso de brinquedos de corda $(p=0,005)$, brinquedos de sucata $(p=0,000)$ e pular corda $(p=0,021)$, mais presentes no Grupo 1. Os resultados sugerem certa influência socioeconômica no brincar de crianças pré-escolares.
\end{abstract}

Palavras-chave: recreação, desenvolvimento, crianças em idade pré-escolar, nível socioeconômico.

\section{Socioeconomic and cultural influence on preschoolers' play}

\begin{abstract}
Assuming that the economic context influences children's play, this study aimed to examine the differences between toys used by children from two different socio-economic classes. Data collection was carried out with 50 mothers of children from three to six years old. According to Critério Brasil, half of the participants belonged to economic level A2 (Group 2) and the other half to economic level D (Group 1). Results indicate that there are significant differences between the use of computers $(p=0.000)$, board games $(p=0.023)$, games of arm $(p=0.042)$, button soccer $(p=0.012)$, more used by Group 2 and the use of clockwork toys $(p=0.005)$, scrap toys $(p=0.000)$ and jump rope $(p=0.021)$, which were more present in Group 1. Results suggest that socioeconomic levels influence playing behaviors of preschooler children.
\end{abstract}

Keywords: recreation, development, preschool age children, socioeconomic status.

\section{La influencia socioeconómica en el comportamiento de juego de preescolares}

\begin{abstract}
Resumen: Considerando que el contexto económico afecta el juego de los niños, este estudio tuvo como objetivo examinar las diferencias entre los juguetes utilizados por niños de dos diferentes clases socioeconómicas. Los datos fueron recogidos en un cuestionario aplicado a 50 madres con niños entre las edades de tres y seis años, siendo la mitad del nivel económico A2 y la otra mitad del nivel económico D según Criterio Brasil. Los resultados apuntan a la existencia de diferencias significativas en relación con el uso de ordenadores $(p=0000)$, juegos de mesa $(p=0023)$, juegos de brazo $(p=0042)$, juego de botón $(p=0012)$, más actual en el Grupo 2 y el uso de los juguetes de cuerda $(p=0005)$, juguetes, chatarra $(p=0000)$, saltar la cuerda $(p=0021)$, más presente en el Grupo 1. Los resultados indican cierta influencia socioeconómica en los juegos de niños preescolares.
\end{abstract}

Palabras clave: recreación, desarrollo, niños en edad pre-escolar, nivel socioeconómico.

O brincar é visto como uma das atividades que mais contribuem para a promoção do desenvolvimento intelectual, social, emocional e físico das crianças (Campos \& Francischini, 2003; Poletto, 2005; Alves \& Gnoato, 2003). É considerado como qualquer atividade espontânea e organizada que proporciona prazer, entretenimento e diversão (American Occupational Therapy Association [AOTA], 2002).

A brincadeira é o melhor meio de a criança estabelecer contato com o mundo ao seu redor, pois oferece oportunidade de prazer, descoberta, mistério, criatividade e autoexpressão, contribuindo com o desenvolvimento infantil (Ferland, 2006). É pelo brincar que a criança inicia seu autoconhecimento, exercita suas potencialidades e pode reviver

1 Endereço para correspondência:

Profa. Dra. Luzia Iara Pfeifer. Universidade de São Paulo. Faculdade de Medicina de Ribeirão Preto. Departamento de Neurociências e Ciências do Comportamento-Divisão de Terapia Ocupacional. Av. Bandeirantes, 3900. CEP 14.048-900. Ribeirão Preto-SP, Brasil. E-mail: luziara@ fmrp.usp.br circunstâncias que lhe causaram excitação, alegria, ansiedade, medo ou raiva (Pedro e cols., 2007).

Segundo Takata (1974), o brincar de crianças pré-escolares engloba o período de jogos simbólicos e construção simples, que vai dos dois aos quatro anos, quando aparece o faz-de-conta, e a recreação deixa de ser solitária e passa a ser paralela; bem como o período de jogos dramáticos, complexos, de construção e pré-competição, que vai dos quatro aos sete anos, quando a criança passa para a recreação associativa; ou seja, participa de um grupo com atividades divididas, expande a participação social, desempenha papéis dramáticos, possui destreza da mão e apresenta construções realistas e complexas por meio do humor verbal.

O brincar está presente em todas as culturas e exerce importante papel sobre os aspectos biopsicossociais do desenvolvimento infantil e, por isso, tem se constituído em fonte instigante de preocupações científicas (Vectore, 2003).

Toda criança brinca, independente de cultura, raça, credo ou classe social (Almeida \& Casarin, 2002). Gosso (2004) afirma que, embora o brincar seja reconhecido como 
uma atividade universal, presente no desenvolvimento infantil de diferentes populações, não se descartam as influências culturais sobre este. Para Stagnitti (2004) e Wanderlind, Martins, Hansen, Macarini e Vieira (2006), o brincar sofre influências tanto do ambiente físico, social, cultural como também das características pessoais de cada criança envolvida na brincadeira. Por ser uma atividade culturalmente definida (Poletto, 2005), contribui para a transmissão e partilha de elementos culturais entre diferentes estratos etários (Pontes \& Magalhães, 2003).

O brincar é parte integrante da infância e, à medida que vão crescendo, as crianças trazem para suas brincadeiras o que vêem, escutam, observam e experimentam, combinando os diversos conhecimentos a que tiveram acesso. As crianças utilizam os brinquedos de diferentes formas, organizando-os de acordo com a cultura na qual estão inseridas, adaptandoos aos seus contextos de vida e expressando, assim, visões de mundo particulares (Carvalho \& Pedrosa, 2002; Goulart \& Sperb, 2003; Meira, 2003; Poletto, 2005).

Pesquisadores buscam resquícios e retratos que permitam associar o fenômeno do brincar ao contexto histórico de diversos grupos sociais, já que os brinquedos evocam as formações do social e revelam, em suas configurações, traços da cultura na qual se inserem (Meira, 2003). O brincar faz parte das ocupações humanas, sendo o principal papel ocupacional - ocupação primária - da criança (Stagnitti \& Unsworth, 2000; Stagnitti, 2004). Desta forma, representa a mais importante atividade humana (desempenho ocupacional) infantil (AOTA, 2002), possibilitando a aquisição de novas habilidades, capacidades e competências.

Toda ocupação é influenciada direta ou indiretamente pelos contextos de desempenho nos quais os sujeitos estão inseridos, podendo ser destacados: o contexto cultural que se refere aos hábitos, às crenças, aos padrões de atividades e comportamentos aceitos pela sociedade da qual fazem parte, além de incluir aspectos políticos, oportunidades para a educação, trabalho e suporte econômico (AOTA, 2002); o contexto social que abrange as redes de interação social com sua família (Cavalcanti \& Galvão, 2007) ou outros grupos sociais maiores que podem influenciar, pelo estabelecimento de normas, expectativas de função e rotinas sociais; e o contexto pessoal que se refere às características como a idade, o sexo, o estado socioeconômico e educacional do sujeito (AOTA, 2002).

Nesse sentido, o objetivo deste trabalho foi identificar as semelhanças e diferenças existentes entre o brincar de crianças pré-escolares pertencentes a duas diferentes classes socioeconômicas, quanto aos tipos de brinquedos utilizados, com base na compreensão de suas mães.

\section{Método}

Este trabalho faz parte de uma pesquisa mais ampla, desenvolvida em 2007, que analisou a influência sociocultural no brincar infantil, por meio da aplicação de um questionário, o roteiro reestruturado de Biasoli-Alves e Graminha (1979), junto às mães de crianças pré-escolares. A escolha de tal instrumento se deu pelo fato dele ser simples, de caráter impessoal e dotado de instruções padronizadas. Isso propiciou sua aplicação a um grande número de mães, bem como o levantamento de informações importantes acerca da identificação do respondente e da criança, das atividades da criança e do contato social, permitindo a compreensão dos sujeitos em seus respectivos contextos.

\section{Participantes}

Participaram desta pesquisa 50 mães de crianças com idade entre três e seis anos, distribuídas em dois grupos, sendo 25 pertencentes à classe socioeconômica de nível $\mathrm{D}$, denominado Grupo 1 (G1); e 25, à classe socioeconômica de nível A2, denominado Grupo 2 (G2), segundo o Critério Brasil (Associação Nacional de Empresas de Pesquisa [ANEP], 2002).

Foram excluídas do rol de entrevistados famílias que não pertenciam às classes socioeconômicas $\mathrm{A} 2 \mathrm{e} \mathrm{D}$, mães de crianças com alguma deficiência e mães que não assinaram o Termo de Consentimento Livre e Esclarecido. Buscando homogeneizar os grupos, não somente pelo nível socioeconômico, mas também pelo contexto social em que os sujeitos da pesquisa residem, a escolha das famílias se deu em uma escola particular e em uma creche municipal, pois acredita-se que o ambiente educacional, no qual estas crianças estão inseridas, também influencia suas escolhas ocupacionais.

\section{Procedimentos}

Inicialmente, as mães foram esclarecidas a respeito da pesquisa e, em concordância com a proposta, solicitava-se a assinatura do Termo de Consentimento Livre e Esclarecido, em seguida, era aplicado o questionário do Critério Brasil. Após esta etapa, era agendada data para aplicação do questionário sobre o brincar, que se deu de modo individualizado e em ambiente que garantia a privacidade da mãe.

Para o presente trabalho, foi utilizada apenas a questão apresentada a seguir, na qual as mães poderiam escolher quantas alternativas fossem verdadeiras: Com quais brinquedos seu filho costuma brincar?( ) Carrinhos, ( ) Jogos de armar (lego,etc. ), ( ) Quebra-cabeça, ( ) Fogãozinho, ( ) Revólver, ( ) Bicicleta; ( ) Tico-tico/velotrol, ( ) Espada, ( ) Boneca, ( ) Brinquedo de dar corda, ( ) Brinquedo de pilha, ( ) Bola, ( ) Livros de histórias, ( ) Livros de recorte e colagem, ( ) Livros de pintar, ( ) Canetas/lápis de cor/ papel/lápis, ( ) Lousa e giz, ( ) Corda, ( ) Jogos coletivos (dominó, torrinha, ludo), ( ) Sucatas, ( ) Disco/fitas/CDs de história, ( ) Bichinhos (plástico/pelúcia), ( ) Forte Apache, ( ) Instrumentos musicais, ( ) Álbum de figurinhas, ( ) Telefone, ( ) Casa de boneca, ( ) Patins, ( ) Massa modelar, ( ) Jogo de botão/ pebolim, ( ) Videogame, ( ) Computador, Outros 


\section{Análise de dados}

Para facilitar a análise dos resultados obtidos, separouse os brinquedos utilizados pelas crianças em seis categorias estabelecidas, de acordo com sua função e/ou característica, sendo estas: brinquedos que estimulam a motricidade global (bicicleta, velotrol/tico-tico, bola, corda, patins, pipa e patinete - sendo que estes dois últimos brinquedos/brincadeira foram citados na alternativa outros do questionário); brinquedos que reportam ações agressivas (espada e revólver); brinquedos pedagógicos (jogos de armar, quebra-cabeça, livros de histórias, discos/fitas/CDs, jogos coletivos, instrumentos musicais, massa de modelar, papel/caneta/lápis de cor, livros de pintar, livros de recortar e colar, lousa e giz); brinquedos eletrônicos (videogame e computador); brinquedos de faz-de-conta (carrinho, fogãozinho, boneca, casinha de boneca, bichinhos de pelúcia/plástico); e demais brinquedos citados (brinquedos de dar corda, álbum de figurinhas, jogo de botão e sucatas).

As alternativas "Forte Apache", "brinquedo de pilha" e "telefone", presentes na questão, não foram citadas e, por isso, não entraram nas categorias de análise. Para análise estatística, os grupos foram comparados, quanto às proporções relativas às brincadeiras, usando-se o Teste Exato de Fisher. $\mathrm{O}$ tipo de teste adotado foi o monocaudal, com nível de significância fixado em $5 \%(p<0,05)$, seguindo-se as indicações de Siegel e Castellan (2006).

\section{Aspectos éticos}

O projeto de pesquisa foi aprovado pelo Comitê de Ética do Hospital Universitário ligado à instituição de ensino superior a qual os pesquisadores são vinculados (processo $\mathrm{n}^{\circ}$ 7839/2005).

\section{Resultados}

Quanto à caracterização da amostra, tem-se que a idade das mães entrevistadas do Grupo 1 variou entre 21 e 63 anos de idade (uma das entrevistadas era a avó da criança, mas responsável legal por ela). Quanto ao grau de escolaridade, $40 \%$ tinham o ensino fundamental 1 (de $1^{\mathrm{a}}$ a $4^{\mathrm{a}}$ séries) incompleto, sendo que a de menor grau de escolaridade era analfabeta (4\%), e a de maior grau de escolaridade tinha o ensino superior incompleto (4\%). Destas, $72 \%$ ocupavamse como empregadas domésticas, as restantes eram apanhadoras de laranja (8\%), auxiliar de produção (4\%), pizzaiolla (4\%), cardegrafista (4\%), pajem (4\%) e auxiliar de confeiteiro $(4 \%)$. Quanto às crianças do Grupo 1 , a maioria $(52 \%)$ era do sexo feminino, $20 \%$ tinham três anos, $32 \%$ quatro anos, $32 \%$ cinco anos e $16 \%$ seis anos de idade, sendo que $72 \%$ delas permaneciam na instituição de ensino, em período integral.

A idade das mães entrevistadas do Grupo 2 variou entre 27 e 46 anos de idade. Quanto ao grau de escolaridade, $80 \%$ concluíram o ensino superior, sendo que a de menor escolaridade possuía o ensino médio incompleto. Destas, $40 \%$ eram profissionais liberais (médicas, dentistas, arquitetas, advogadas), 20\% exerciam atividades ligadas à educação (professoras, pedagogas e coordenadoras pedagógicas) e as demais exerciam as atividades de comerciantes $(12 \%)$, empresárias $(12 \%)$, farmacêutica (4\%), zootecnista (4\%), oficial de justiça (4\%), apenas uma mãe não trabalhava fora de casa (4\%). Quanto às crianças do Grupo 2, a maioria $(60 \%)$ era do sexo masculino, $24 \%$ tinham três anos de idade, $28 \%$ quatro anos, $32 \%$ cinco anos e $16 \%$ tinham seis anos, sendo que $72 \%$ estudavam, no período matutino e $28 \%$, no período vespertino.

Quanto aos brinquedos que estimulam a motricidade global das crianças (Figura 1), tem-se que as crianças andam de bicicleta (G1: $80 \%$ e G2: 72\%), de patins (G1: $12 \%$ e G2: 20\%), de velotrol/tico-tico (G1: $68 \%$ e G2: $56 \%$ ), de patinete (G1: $0 \%$ e G2: $12 \%$ ), jogam bola (G1: $72 \%$ e G2: $84 \%$ ), soltam pipa (G1: $8 \%$ e G2: $0 \%$ ) e pulam cordas (G1: $56 \%$ e G2: $24 \%)$.

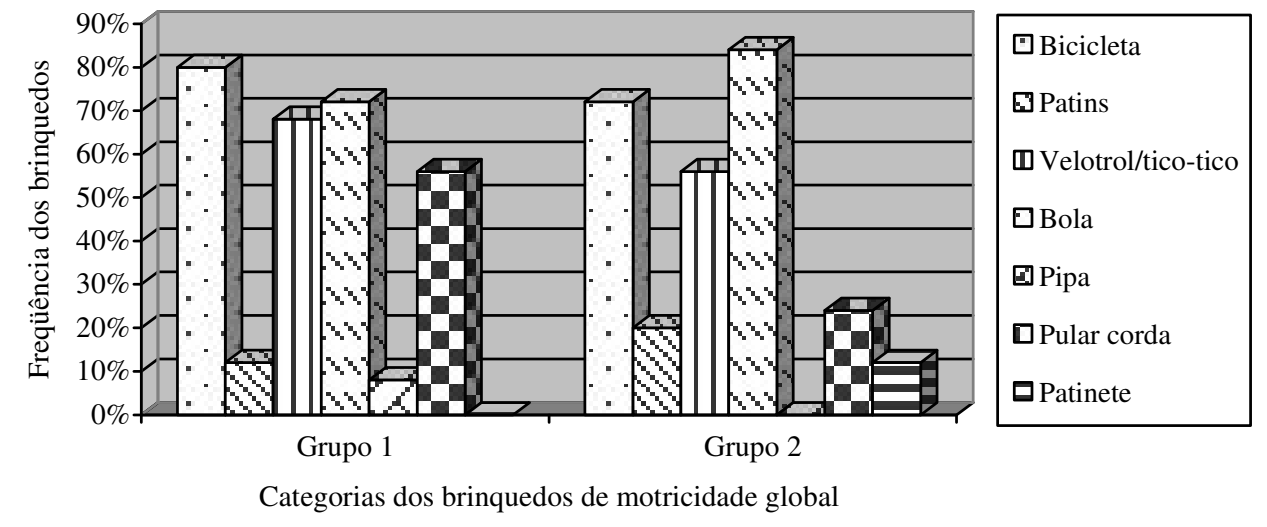

Figura 1. Distribuição dos brinquedos que estimulam a motricidade global em cada grupo. 
Observa-se que a preferência de ambos os grupos está em brincar com bola, seguida por bicicleta. A diferença significativa encontrada foi unicamente com relação ao pular corda $(p=0,021)$, atividade esta mais citada pelo Grupo 1 .

Em relação aos brinquedos que reportam ações agressivas, tem-se que as crianças brincam com revólver de brinquedo (G1: $8 \%$ e G2: $8 \%$ ) e com espadas de brinquedo (G1: 16\% e G2: 32\%), o que demonstra baixa aceitação dos pais, de ambos os grupos, em relação aos brinquedos desta espécie, não havendo diferença significativa entre os grupos analisados.

Levando em consideração os brinquedos pedagógicos
(Figura 2), tem-se que as crianças brincam com jogos de armar (G1: 44\% e G2: 72\%), com quebra-cabeças (G1: 56\% e G2: 72\%), lêem/escutam livros de história (G1: 76\% e G2: $92 \%$ ), escutam discos/fitas/CDs que narram contos (G1: $36 \%$ e G2: $48 \%$ ), brincam com jogos coletivos, tais como: dominó, ludo, dentre outros (G1: 28\% e G2: 60\%), com instrumentos musicais (G1: 60\% e G2: 64\%), com massa de modelar (G1: 68\% e G2: 56\%), usam papel/canetas/lápis de cor (G1: $96 \%$ e G2: 88\%), livros de pintar (G1: $80 \%$ e G2: $80 \%$ ), livros de recortar e colar (G1: $52 \%$ e G2: $44 \%$ ), e lousa e giz (G1: $40 \%$ e G2: $28 \%$ ).
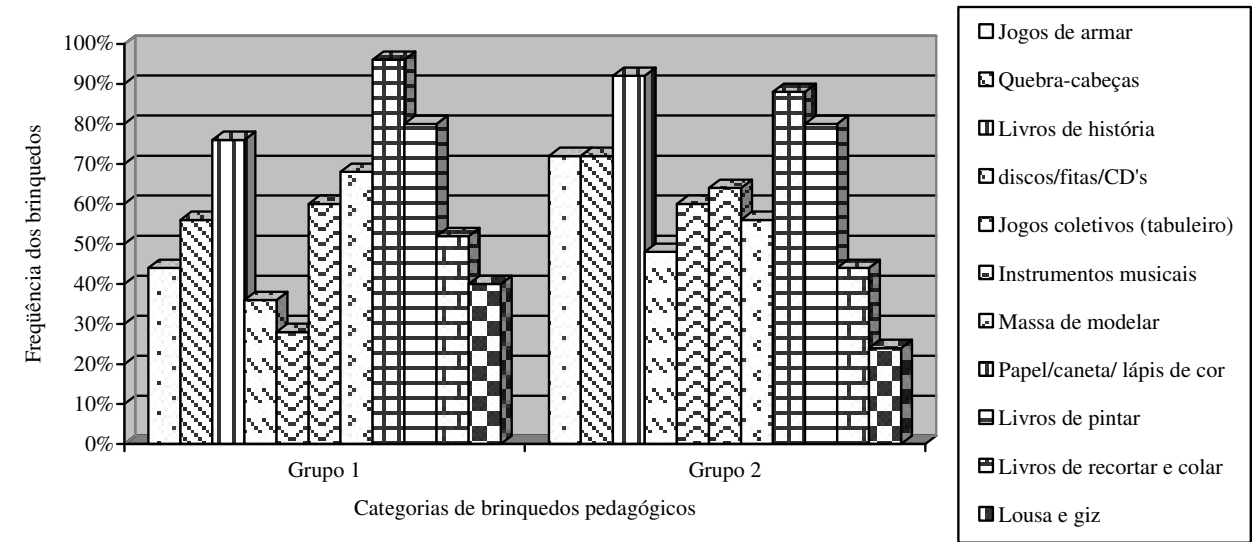

Figura 2. Distribuição dos brinquedos pedagógicos em cada grupo.

Nota-se que há grande aceitação/uso, por parte das crianças de ambos os grupos, aos brinquedos dessa categoria, sendo encontradas diferenças significativas entre eles, apenas com relação ao uso dos jogos coletivos $(\operatorname{com} p=0,023)$ e aos brinquedos de armar $(p=0,042)$, estando estes mais presentes entre as crianças do Grupo 2.

Quanto aos brinquedos eletrônicos, tem-se que crianças brincam com videogame (G1: $32 \%$ e G2: 20\%). Entretanto, no que tange ao uso de computadores, $52 \%$ das crianças do Grupo 2 e nenhuma criança do Grupo 1 têm contato com esse equipamento. Portanto, com relação aos brinquedos eletrônicos, nota-se diferença significativa quanto ao uso do computador entre os grupos analisados, $\operatorname{com} p=0,000$.

Quanto aos brinquedos de faz-de-conta (Figura 3), observa-se que as crianças brincam com carrinho (G1: 76\% e G2: 64\%), com fogãozinho (G1: $32 \%$ e G2: $28 \%$ ), com boneca (G1: $44 \%$ e G2: $28 \%$ ), com casinha de boneca (G1: $36 \%$ e G2: $28 \%$ ) e com bichinhos de plástico/pelúcia (G1: $60 \%$ e G2: 48\%). Em relação aos demais brinquedos citados (Figura 3), observa-se que as crianças utilizam brinquedos de corda (G1: $28 \%$ e G2: $0 \%$ ), têm álbum de figurinhas (G1: 28\% e G2: 48\%), brincam com jogo de botão ou de pebolim (G1: $4 \%$ e G2: $32 \%$ ) e brincam com brinquedos a partir de sucatas (G1: $68 \%$ e G2: 12\%).

Novamente, observam-se diferenças significativas, com relação ao uso de determinados brinquedos, em detrimento da condição econômica das crianças pertencentes aos grupos analisados, como nos jogos de botão $(p=0,012)$, brinquedos de corda $(p=0,005)$ e com relação ao uso de sucatas no brincar $(p=0,000)$.

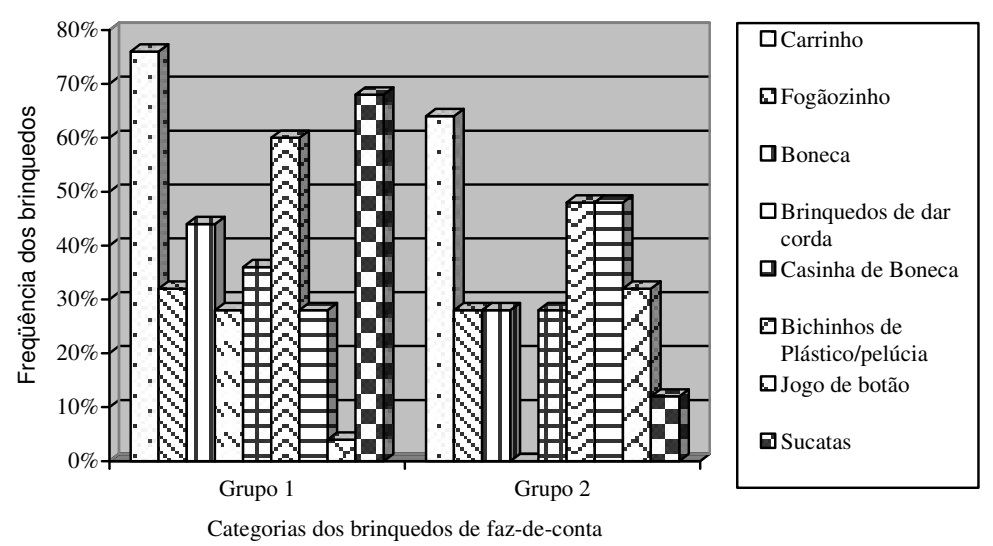

Figura 3. Distribuição dos brinquedos de faz-de-conta e demais brinquedos citados em cada grupo. 


\section{Discussão}

No que tange à caracterização da amostra, verifica-se que há grande diferença entre o grau de escolaridade das mães do Grupo 1 e Grupo 2, o que repercute, também, em suas ocupações profissionais. Estudos reforçam que níveis de instrução, assim como os de renda mais alta, possibilitam às mulheres maior acesso a informações em geral, contribuindo com melhor cuidado oferecido aos filhos (Mello \& Ferriani, 1996).

Quanto às crianças, a única diferença significativa se dá pelo fato de que aquelas pertencentes ao Grupo 1 permanecem, em sua maioria, em período integral na escola, o que não acontece com as crianças do Grupo 2. O brincar é um conceito histórico e social que é apreendido pelas crianças por meio das relações. Assim, a família, a escola e a sociedade acabam direcionando as escolhas do sujeito (Gomes \& Cunha, 2005). Desta forma, é possível que a influência do ambiente escolar seja maior nas crianças do Grupo 1 , já que passam a maior parte de seu dia em contato com seus educadores e menos com seus familiares.

Em relação ao uso de brinquedos que estimulam a motricidade global, os dados demonstram que as crianças préescolares do presente estudo preferem a bicicleta, o velotrol/ tico-tico e a bola, sem diferenças significativas entre os grupos. A alta frequência no uso da bicicleta como brinquedo vai ao encontro dos estudos de Lopes e Pires Neto (2001), no qual destacam o andar de bicicleta como sendo uma das brincadeiras preferidas entre meninos e meninas, estes pesquisadores também apontam para o alto índice de uso da bola pelos meninos.

O pular corda foi a única brincadeira que apresentou diferença significativa nesta categoria, estando mais presente no Grupo 1. Não se identifica nenhum argumento que explique a presença desta atividade lúdica mais frequente no grupo de crianças de baixa renda, a não ser o fato de a corda ser um brinquedo de baixo custo e que pode ser utilizado em quintais, calçadas e mesmo no pátio da escola. Dentre os brinquedos que reportam ações agressivas (revólver e espada), nota-se que há baixa aceitação em ambos os grupos, sem diferenças significativas. Toda brincadeira pressupõe uma aprendizagem social (Pontes \& Magalhães, 2003), logo, pode-se inferir que as mães, participantes deste estudo, buscam evitar o contato dos filhos com brinquedos que estimulam a agressividade.

Quanto ao uso de brinquedos pedagógicos, observa-se grande aceitação/uso destes por parte das crianças de ambos os grupos, principalmente com relação ao uso de papel/ canetas/lápis de cor, livros de histórias e livros de pintura. A inserção da criança na escola, ainda em idade pré-escolar, facilita contato com esses recursos lúdicos. Neste aspecto, as escolas devem servir de local facilitador, para que as atividades lúdicas possam ocorrer, uma vez que estas podem contribuir grandemente para o desenvolvimento de aspectos cognitivos e sociais, bem como com a capacidade das crianças para lidar com diversas circunstâncias da vida (Poletto, 2005).
Houve diferenças significativas somente com relação ao uso dos jogos coletivos (tabuleiro) e dos brinquedos de armar (tipo "Lego"), por serem estes de custo mais elevado, o que dificulta a aquisição por parte das crianças do Grupo 1. Com relação ao uso de brinquedos eletrônicos, nota-se grande disparidade entre as crianças pertencentes aos dois grupos, uma vez que mais da metade daquelas pertencentes ao Grupo 2 faz uso sistemático do computador, enquanto nenhuma criança do Grupo 1 tem acesso a este equipamento, que apresenta alto custo, incompatível com o orçamento das famílias participantes deste grupo.

O quadro acima configurado se inverte com relação ao uso do videogame, sendo este mais utilizado entre as crianças do Grupo 1, entretanto, a frequência é bem mais baixa (32\% da amostra do Grupo 1). Esta pesquisa não focalizou o tempo despendido pela criança em atividades que utilizam os brinquedos eletrônicos, nem mesmo o tipo de jogos desenvolvidos nestas atividades, que podem apresentar contextos agressivos.

Meira (2003) destaca que, ao passar horas a fio do seu dia-a-dia, em frente aos aparelhos virtuais, a saber, televisão, videogame, computador, dentre outros, as crianças acabam por ter seu brincar sucumbido, na medida em que realizam movimentos corporais mais restritos, reduzindo também a capacidade de criar e abstrair. Outro aspecto a ser destacado é que, atualmente, o uso indiscriminado desses aparelhos, sem controle efetivo dos pais, tem causado acesso descontrolado a informações do universo adulto, por parte das crianças, fazendo com que estas passem a vivenciar de maneira natural e espontânea o jogo da sensualidade, o uso da violência, da mentira e os hábitos consumistas desenfreados na busca pelo prazer (Salles, 2005; Postman, 2005).

$\mathrm{Na}$ análise feita com os brinquedos de faz-de-conta, destacam-se as brincadeiras com carrinhos e de bichinhos de pelúcia/plástico por ambos os grupos. As outras atividades de faz-de-conta foram menos citadas, mas mantiveram a média de 28 a $44 \%$ em ambos os grupos. O faz-de-conta começa a se desenvolver ao final do primeiro ano e durante o segundo ano de vida, tendo seu apogeu por volta do quinto ano, evoluindo, então, para o brincar dramático e sociodramático (Knox, 2005). Por meio do faz-de-conta, a criança assume papéis presentes no seu cotidiano e, desta forma, pode verificar as consequências por agir de um ou de outro modo, permitindo a internalização de regras de conduta e desenvolvendo um sistema de valores que irá orientar seu comportamento (Guimarães, Pereira, \& Emmel, 2002).

Quanto aos demais brinquedos citados, foram identificadas diferenças significativas apenas com o jogo de botão, mais frequente entre as crianças do Grupo 2, e em relação aos brinquedos de corda e aos brinquedos confeccionados a partir de sucatas, mais frequentes entre as crianças do Grupo 1.

É importante ressaltar que, em uma época em que os brinquedos tendem a ser homogêneos e totalmente plastificados, industrializados, o uso de sucatas no brincar vem contribuir para o renascimento dos processos criativos e lúdicos das crianças, pois, a partir de materiais como madeira, 
tecidos, argila e materiais recicláveis, estas têm a oportunidade de construir brinquedos singulares, únicos, sobre os quais podem imprimir suas características. Atualmente, a excessiva utilização e preferência por brinquedos industrializados devem ser investigadas quanto à possibilidade desses restringirem a capacidade de criação e resolução de problemas. A baixa referência do Grupo 2 quanto ao uso dos brinquedos de criação sugere que há pouca estimulação e valorização da criatividade nas crianças, que poderia ser incentivada pelos ambientes em que as crianças interagem diretamente, como no lar, na escola, dentre outros (Poletto, 2005).

\section{Considerações finais}

Este artigo teve por objetivo analisar as diferenças existentes no brincar de crianças provenientes de duas classes socioeconômicas distintas, levando em conta os tipos de brinquedos utilizados por elas. É importante ressaltar que as informações obtidas nesta pesquisa acerca do comportamento lúdico das crianças provêm de uma única fonte, as mães, o que pode resultar certa limitação à pesquisa.

Dos 31 tipos de brinquedos e brincadeiras sinalizados pelas mães participantes, sete apresentaram diferenças significativas entre os grupos. Nota-se que, entre as crianças do Grupo 2, há maior acesso a brinquedos mais estruturados e de custo mais elevado (uso do computador, jogos de tabuleiro, jogos de armar e jogo de botão), se comparado às crianças do Grupo 1, que têm maior acesso a brinquedos menos sofisticados e de baixo custo (brinquedos de dar corda, brinquedos de sucata e pular corda), o que sugere certa influência do nível socioeconômico no brincar de crianças pré-escolares.

Alguns fatores apontados pela presente pesquisa levam à reflexão acerca das consequências para o desenvolvimento e a aprendizagem das crianças que, devido ao fato de serem menos ou mais abastadas economicamente, se veem privadas de determinadas experiências no brincar, como no caso do uso de computadores pelas crianças do Grupo 1 e de sucatas pelas crianças do Grupo 2, em ambas situações, estas crianças saem perdendo, no que se refere à aquisição de novos saberes e habilidades.

Para concluir, é importante ressaltar que, em ambos os grupos, notou-se, por parte das mães, uma preocupação em oferecer aos filhos condições ambientais e materiais, para que o brincar deles ocorra da maneira mais natural e saudável possível, no intuito de promover, ao máximo, dentro de suas condições socioeconômicas, o desenvolvimento de suas crianças.

\section{Referências}

Almeida, D. M., \& Casarin, M. M. (2002). A importância do brincar para a construção do conhecimento na educação infantil. Cadernos de Educação Especial, 19, 45-54.

Alves, A. M. P., \& Gnoato, G. (2003). O brincar e a cultura: Jogos e brincadeiras na cidade de Morretes na década de 1960. Psicologia em Estudo, 8(1), 111-117.
American Occupational Therapy Association. (2002). Occupational therapy practice framework: Domain and process. American Journal of Occupational Therapy, 56, 609-633.

Associação Nacional de Empresas de Pesquisa. (2002). Critério de classificação econômica Brasil. Recuperado em 03 março 2007, de http://www.anep.org.br

Biasoli-Alves, Z. M. M., \& Graminha, S. S. V. (1979). Roteiro reestruturado de entrevista. Manuscrito não-publicado, Universidade de São Paulo, Ribeirão Preto, SP.

Campos, R. H., \& Francischini, R. (2003). Trabalho infantil produtivo e desenvolvimento humano. Psicologia em Estudo, 8(1), 119-129.

Carvalho, A. M. A., \& Pedrosa, M. I. (2002). Cultura no grupo de brinquedos. Estudos de Psicologia (Natal), 7, 181-188.

Cavalcanti, A., \& Galvão, G. (2007). Avaliação dos contextos. In A. Cavalcanti \& G. Galvão (Orgs.), Terapia ocupacional: Fundamentação e prática (pp. 106-111). Rio de Janeiro: Guanabara Koogan.

Ferland, F. (2006). O modelo lúdico: O brincar, a criança com deficiência física e a terapia ocupacional. São Paulo: Rocca.

Gomes, R. F. F., \& Cunha, B. B. B. (2005). Infância e diversidade: Um estudo sobre significações de gênero no brincar. Dissertação de mestrado não-publicada, Universidade Estadual Paulista, Assis, SP.

Gosso, Y. (2004). Pexe oxemoarai: Brincadeiras infantis entre os indios Parakanã. Tese de doutorado nãopublicada, Instituto de Psicologia da Universidade de São Paulo, São Paulo, SP.

Goulart, C. M. T., \& Sperb, T. M. (2003). Histórias de crianças: As narrativas de crianças asmáticas no brincar. Psicologia: Reflexão e Crítica, 16, 355-365.

Guimarães, A. E. O., Pereira, E. C., \& Emmel, M. L. G. (2002). A brincadeira simbólica nas situações lúdicas de crianças portadoras de necessidades especiais e crianças normais. Temas sobre Desenvolvimento, 11, 5-13.

Knox, S. H. (2005). Play. In J. Case-Smith (Ed.), Occupational therapy for children (pp. 571-586). Philadelphia: Elsevier Mosby.

Lopes, A. S., \& Pires-Neto, C. S. (2001). Estilo de vida de crianças com diferentes características étnico-culturais do Estado de Santa Catarina, Brasil. Revista Brasileira de Atividades Físicas e Saúde, 6(3), 6-16.

Meira, A. M. (2003). Benjamin, os brinquedos e a infância contemporânea. Psicologia e Sociedade, 15(2), 74-87.

Mello, D. F., \& Ferriani, M. G. C. (1996). Estudo exploratório de opiniões de mães sobre a saúde das crianças menores de 5 anos. Revista Latino-americana de Enfermagem, 4(2), 87-100.

Pedro, I. C. S., Nascimento, L. C., Poleti, L. C., Lima, R. A. G., Mello, D. F., \& Luiz, F. M. R. (2007). O brincar em sala de espera de um ambulatório infantil na perspectiva de crianças e seus acompanhantes. Revista Latinoamericana de Enfermagem, 15, 290-297. 
Poletto, R. C. (2005). A ludicidade da criança e sua regulação com o contexto familiar. Psicologia em Estudo, 10, 67-75.

Pontes, F. A. R., \& Magalhães, C. M. C. (2003). A transmissão da cultura da brincadeira: Algumas possibilidades de investigação. Psicologia: Reflexão e Crítica, 16, 117-124.

Postman, N. (2005). O desaparecimento da infância. Rio de Janeiro: Graphia.

Salles, L. M. F. (2005). Infância e adolescência na sociedade contemporânea: Alguns apontamentos. Estudos da Psicologia, 22, 33-41.

Siegel, S., \& Castellan, N. J., Jr. (2006). Estatística nãoparamétrica para ciências do comportamento. Porto Alegre: Artmed.

Stagnitti, K. (2004). Understanding play: The implications for play assessment. Australian Occupational Therapy Journal, 51, 3-12.

Stagnitti, K., \& Unsworth, C. (2000). The importance of pretend play in child development: an occupational therapy perspective. British Journal of Occupational Therapy, 63, 121-127.

Takata, N. (1974). Play as a prescription. In M. Reilly (Ed.), Play as exploratory learning (pp. 209-246). Beverly Hills, CA: Sage Publications.

Vectore, C. (2003). O brincar e a intervenção mediacional na formação continuada de professores de educação infantil. Psicologia USP, 14(3), 105-131.

Wanderlind, F., Martins, G. D. F., Hansen, J., Macarini, S. M., \& Vieira, M. L. (2006). Diferenças de gênero no brincar de crianças pré-escolares e escolares na brinquedoteca. Paideia (Ribeirão Preto), 16, 263-273.

Luzia Iara Pfeifer é Professora Doutora da Faculdade de Medicina de Ribeirão Preto da Universidade de São Paulo.

Patrícia Gonçalves Rombe é terapeuta ocupacional graduada pela Faculdade de Medicina de Ribeirão Preto da Universidade de São Paulo, bolsista FAPESP.

Jair Licio Ferreira Santos é Professor Titular da Faculdade de Medicina de Ribeirão Preto da Universidade de São Paulo.

Recebido: 10/01/2008

$1^{a}$ revisão: 03/06/2008

$2^{a}$ revisão: $24 / 07 / 2008$

$3^{a}$ revisão: 22/01/2009

Aceite final: 13/05/2009 